\title{
Only peak thyroglobulin concentration on day 1 and 3 of rhTSH-aided RAl adjuvant treatment has prognostic implications in differentiated thyroid cancer
}

\author{
Aleksandra Ledwon ${ }^{1}$ (1) Ewa Paliczka-Cieślik ${ }^{1} \cdot$ Aleksandra Syguła $^{1} \cdot$ Tomasz Olczyk $^{1} \cdot$ Aleksandra Kropińska $^{1}$.

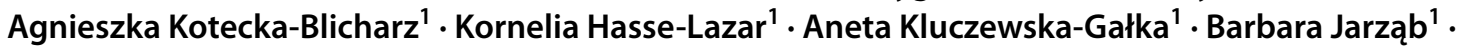 \\ Daria Handkiewicz-Junak ${ }^{1}$
}

Received: 9 May 2021 / Accepted: 29 July 2021 / Published online: 7 August 2021

(c) The Author(s) 2021

\begin{abstract}
Objective In patients with differentiated thyroid carcinoma (DTC), serum thyroglobulin levels measured at the time of remnant ablation after thyroid hormone withdrawal were shown to have prognostic value for disease-free status. We sought to evaluate serial thyroglobulin measurements at the time of recombinant human thyroid-stimulating hormone (rhTSH)-aided iodine $131\left({ }^{131} \mathrm{I}\right)$ adjuvant treatment as prognostic markers of DTC.

Methods Six hundred-fifty patients with DTC given total/near-total thyroidectomy and adjuvant radioiodine post-rhTSH stimulation were evaluated. Thyroglobulin was measured on day 1 ( $\mathrm{Tg} 1$; at the time of the first rhTSH injection), day 3 ( $\operatorname{Tg} 3$; 1 day after the second, final rhTSH injection), and day 6 ( $\operatorname{Tg} 6 ; 3$ days post-radioiodine administration). Treatment failure was defined as histopathologically confirmed locoregional recurrence, or radiologically-evident distant metastases (signs of disease on computer tomography (CT) or magnetic resonance imaging (MRI), or abnormal foci of radioiodine or $\left[{ }^{18} \mathrm{~F}\right]$ fluorodeoxyglucose $\left(\left[{ }^{18} \mathrm{~F}\right] \mathrm{FDG}\right)$ uptake.

Results In univariate analysis, $\operatorname{Tg} 1(p<0.001)$ and $\operatorname{Tg} 3(p<0.001)$, but not $\operatorname{Tg} 6$, were significantly associated with structural recurrence. In multivariate analysis of the overall cohort, only $\operatorname{Tg} 3$ was independently associated with structural recurrence. In multivariate analysis of the subgroup $(n=561)$ with anti-Tg antibodies titers below the institutional cut-off, $115 \mathrm{IU} / \mathrm{mL}$, $\mathrm{Tg} 1$ was an independent prognostic marker. $\operatorname{Tg} 1$ and $\operatorname{Tg} 3$ cutoffs to best predict structural recurrence were established at $0.7 \mathrm{ng} / \mathrm{mL}$ and $1.4 \mathrm{ng} / \mathrm{mL}$, respectively.

Conclusions $\mathrm{Tg} 1$ and $\mathrm{Tg} 3$, measurements made after rhTSH stimulation but before radioiodine treatment, independently predict a low risk of treatment failure in patients with DTC. Levels measured post-radioiodine application (e.g., Tg6) are highly variable, lack prognostic value, and hence can be omitted.
\end{abstract}

Keywords Differentiated thyroid carcinoma (DTC) $\cdot$ Thyroglobulin $(\mathrm{Tg}) \cdot$ Radioiodine (RAI) $\cdot$ Recombinant human thyroid-stimulating hormone $($ rhTSH) $\cdot$ Prognostic marker $\cdot$ Structural recurrence

\section{Introduction}

In patients with differentiated thyroid cancer (DTC), stimulated serum thyroglobulin ( $\mathrm{Tg}$ ) concentration measured around the time of radioiodine (RAI) treatment is a

Aleksandra Ledwon

aleksandra.ledwon@gmail.com

1 Department of Nuclear Medicine and Endocrine Oncology, Maria Sklodowska-Curie National Research Institute of Oncology, Gliwice Branch, Gliwice, Poland valuable prognostic factor for persistent/recurrent disease [1-5]. Given the analyte's approximately 65 -h half-life, serum $\mathrm{Tg}$ levels should in theory drop to undetectable approximately 1 month after total thyroidectomy. However, even after such surgery, $\mathrm{Tg}$ level is variable and may depend on thyroid remnant volume and thyroid-stimulating hormone (TSH) concentration. Tg cutoff values are also dependent on the TSH stimulation method. Stimulated Tg cutoffs have mainly been established in patients undergoing thyroid hormone withdrawal (THW) [6-8]. In contrast, data on optimal measurement times and on the prognostic value of the Tg level after recombinant human 
TSH (rhTSH) stimulation are rather limited [9-12]. Only one report has compared measurements taken at different points around the time of rhTSH stimulation [13]. In diagnostic settings, the highest prognostic value of Tg measurement is 5 days after the first rhTSH injection $[14,15]$. However, in the adjuvant RAI therapy setting, concern has been raised because Tg levels are affected not only by residual cancer cells but mostly by remnant thyrocytes, especially after RAI-induced thyrocyte damage [16]. On the other hand, some studies showed that the ratio of preRAI (at RAI administration) to post-RAI (5 days posttherapy) $\mathrm{Tg}$ measurements is of prognostic significance [17]. The question of when is the best time to measure $\mathrm{Tg}$ during rhTSH-aided adjuvant RAI treatment remains open.

After introducing rhTSH-aided adjuvant RAI treatment in patients with DTC, we selected Tg measurement on day 1,3 , and 6 starting with the first rhTSH injection. However, as our clinical experience with rhTSH grew, we noticed that in patients with thyroid remnant, in contrast to those receiving repeated treatment for metastases, $\operatorname{Tg} 6$ appeared to be highly variable and not to correlate with clinical outcome. The present study was undertaken to evaluate in a large cohort of patients with DTC the optimal time(s) during rhTSH-aided adjuvant RAI therapy to measure $\mathrm{Tg}$ concentration. We also sought to define the prognostic significance of $\mathrm{Tg}$ measurements during this period.

\section{Materials and methods}

We retrospectively reviewed records of patients who underwent adjuvant RAI treatment after rhTSH stimulation from 2008 to 2011. Six hundred-fifty patients with DTC after total/near-total thyroidectomy, without persistent disease and treated for the first time with rhTSH-aided RAI, were included in the analysis. Cases of persistent disease were excluded based on neck ultrasound, post-therapy scintigraphy, and/or chest x-ray. In case of elevated ( $>10 \mathrm{ng} / \mathrm{mL}$ ) Tg during TSH suppression, neck and chest CT was done, and if this imaging was negative, patients were also included in the study. During radioiodine therapy, thyroid remnant volume on neck ultrasound performed on day 1 of rh-TSH stumulation was $<2 \mathrm{~mL}$ in all except five patients. In those individuals, due to additional medical conditions, RAI therapy was given without completion thyroidectomy. Patient characteristics are summarized in Table 1.

rhTSH application as preparation for RAI therapy was approved by the Ethics Review Committee of our institution. As a retrospective analysis in which all patient information was de-identified, this study was determined to be exempt from approval by our Institutional Review Board.

\section{Treatment protocol and follow-up}

According to institutional guidelines at the time of treatment, all patients, except those with pT1aNOM0 papillary thyroid cancer, were referred for RAI adjuvant therapy. Median time from surgery to such therapy was 80 (13-370) days, and median administered RAI activity was $3.7 \mathrm{GBq}[100 \mathrm{mCi}]$ (minimum-maximum: 3.7-5.55 GBq [100-150 mCi]). All patients were hospitalized in a radionuclide therapy department with full radiation protection for at least 3 days after RAI administration, then discharged when the radiation dose rate at $1 \mathrm{~m}$ was $<20 \mathrm{mSv} / \mathrm{h}$.

$\mathrm{Tg}$ measurement was performed on day 1 ( $\mathrm{Tg} 1$; just before the first injection of rhTSH, $0.9 \mathrm{mg}$ ), on day $3(\mathrm{Tg} 3$; one day after the second, final injection of rhTSH, $0.9 \mathrm{mg}$ ), and on day 6 (Tg6; 48 and $120 \mathrm{~h}$, respectively, after the first rhTSH injection, and three days after RAI administration). Seventy-two hours after ${ }^{131} \mathrm{I}$ administration, whole-body scintigraphy (WBS) was performed (Supplementary Fig. 1). When RAI uptake outside the thyroid bed was suspected, single-photon emission computed tomography fusion imaging (SPECT/CT) was used to clarify the region of uptake.

After RAI treatment, all patients were followed-up with neck ultrasound and $\mathrm{TSH}, \mathrm{Tg}$, and anti-Tg antibodies (TgAbs) determinations at 6-month to 18-month intervals. Other examinations were performed as indicated. TSH level was kept within 0.1-0.4 uIU/mL. Stimulated Tg and diagnostic ${ }^{131}$ I WBS was performed 12-24 months after RAI treatment to assess that modality's efficacy. Median followup for the study sample was 6 years (minimum-maximum: 5-8 years).

\section{Biochemical measurements}

Serum $\mathrm{Tg}$ was measured via chemiluminescence assay (Roche Diagnostic, Meylan, France), which during the time of treatment, had an analytical sensitivity of $0.1 \mathrm{ng} / \mathrm{mL} 1$ or $0.04 \mathrm{ng} / \mathrm{ml}$ (from 2014) and functional sensitivity $<1 \mathrm{ng} / \mathrm{mL}$. Serum $\operatorname{TgAbs}$ were measured with the Roche Diagnostic Elecsys assay, with an analytical sensitivity of $10 \mathrm{IU} / \mathrm{mL}$ and a reference value of $10-4000 \mathrm{IU} / \mathrm{mL}$.

\section{Imaging methods}

Ultrasound was performed with a linear multifrequency 10-MHz transducer for morphological analysis and for Doppler evaluation. All suspicious findings were submitted to ultrasound-guided fine-needle aspiration biopsy. 
Table 1 Patient characteristics

\begin{tabular}{|c|c|c|}
\hline Characteristic & $\begin{array}{l}\text { Whole group of patients }(N=650) \\
(\%)\end{array}$ & $\begin{array}{l}\text { Subgroup with } \operatorname{TgAbs} \text { below } \\
\text { institutional cutoff }(n=561)(\%)\end{array}$ \\
\hline Gender: female/male & $535(82.3) / 115(17.7)$ & $455(81.1) / 106(18.9)$ \\
\hline Age (yr): median (minimum-maximum) & $53(13-85)$ & $54(16-86)$ \\
\hline Total/near-total thyroidectomy & $595(91.5) / 55(8.5)$ & $511(92) / 50(8)$ \\
\hline Central lymph node dissection & $341(52.5)$ & $288(51)$ \\
\hline Lateral lymph node dissection & $68(10.5)$ & $56(10)$ \\
\hline \multicolumn{3}{|l|}{ TNM classification (7th edition) } \\
\hline \multicolumn{3}{|l|}{ Primary tumor } \\
\hline T0 & $3(0.5)$ & $3(0.5)$ \\
\hline $\mathrm{T} 1$ & $362(55.7)$ & $310(55.3)$ \\
\hline $\mathrm{T} 2$ & $82(12.6)$ & $72(12.8)$ \\
\hline 3 & $142(21.8)$ & $123(21.9)$ \\
\hline Intrathyroidal tumor $>4 \mathrm{~cm}$ in greatest dimension & $26(4)$ & $25(4.4)$ \\
\hline Extrathyroidal extension & $116(17.8)$ & $98(17.5)$ \\
\hline $\mathrm{T} 4$ & $7(1.1)$ & $4(0.8)$ \\
\hline $\mathrm{Tx}$ & $54(8.3)$ & $49(8.7)$ \\
\hline \multicolumn{3}{|l|}{ Lymph node } \\
\hline No & $241(37.1)$ & $208(37.1)$ \\
\hline N1 & $137(21.1)$ & $109(19.4)$ \\
\hline N1a & $74(11.4)$ & $59(10.5)$ \\
\hline $\mathrm{N} 1 \mathrm{~b}$ & $63(9.7)$ & $50(8.9)$ \\
\hline $\mathrm{Nx}$ & $272(41.8)$ & $244(43.5)$ \\
\hline \multicolumn{3}{|l|}{ Histology } \\
\hline Papillary & $577(88.8)$ & $495(88.2)$ \\
\hline Papillary-aggressive variant ${ }^{\mathrm{a}}$ & $15(2.3)$ & $12(2.1)$ \\
\hline Follicular & $52(8)$ & $48(8.6)$ \\
\hline Poorly differentiated & $6(0.9)$ & $6(1.1)$ \\
\hline Multifocality & $153(23.5)$ & $129(23)$ \\
\hline
\end{tabular}

TgAbs anti-thyroglobulin antibodies

${ }^{a}$ Includes solid variant, tall cell variant, columnar cell variant, and diffuse sclerosing variant

Post-therapy WBS and, when required, spot or SPECT imaging, were performed $72 \mathrm{~h}$ after ${ }^{131} \mathrm{I}$ treatment, with a dual-head gamma camera (Multispect 2 or E.Cam-Duet, Siemens, Erlangen, Germany) equipped with parallel highenergy collimators. All non-physiological areas of iodine uptake outside the thyroid bed were considered to be positive findings for DTC metastases, and patients were not included in the study.

\section{Definition and diagnosis of treatment failure}

For the purpose of the study, only structural recurrences were considered as treatment failure. If structural recurrence was suspected on neck ultrasound, fine-needle biopsy was performed, with histopathological evidence of such recurrence considered to be confirmatory. At sites outside the neck, CT, MRI or $\left[{ }^{18} \mathrm{~F}\right] \mathrm{FDG}$ PET/CT were the gold standard to confirm metastatic disease. The indication for radiological examination was an increasing $\mathrm{Tg}$ level or abnormal findings in clinical examinations.

\section{Statistics}

Quantitative data are expressed as mean \pm SD (standard deviation). Between-group differences were assessed by two-tailed unpaired $t$ test. The predictive value of $\mathrm{Tg}$ with respect to different clinical variables was assessed by univariate and multivariate Cox proportional hazards modeling. The cutoff values to optimally predict structural recurrence for Tg measured at different time intervals during RAI treatment were selected by analyzing Receiver Operating Characteristic (ROC) curves. Diagnostic performance (sensitivity, specificity, positive predictive value [PPV] and negative predictive value [NPV]) of Tg was evaluated based on the 
cutoff values obtained by ROC curve analysis. KaplanMayer curves were used for survival analysis. $\mathrm{R}$ software ( $\mathrm{R}$ Foundation, Vienna, Austria) was used for statistical analysis. Statistical significance was defined by a $p$ value $<0.05$.

\section{Results}

\section{Biochemical evaluation}

At the time of RAI treatment, $\mathrm{TgAbs}$ were detectable in 343 patients $(53 \%)$ and were above the institutional cutoff of $115 \mathrm{IU} / \mathrm{mL}$ in $89(14 \%)$. There was a statistically significant negative correlation between $\mathrm{Tg}$ concentration and $\mathrm{TgAbs}$ level, but the coefficient of correlation was very weak: -0.179 on day $1,-0.180$ on day 3 , and -0.135 on day 6 (Supplementary Fig. 2). Due to this weak but significant correlation, we performed all analyses first in the whole group of patients $(N=650)$ and then in a subgroup with TgAbs below the institutional cutoff $(n=561)$.

Median $\mathrm{Tg}$ concentration on day 1 , day 3 , and day 6 increased from $0.2 \mathrm{ng} / \mathrm{mL}$ to $1.0 \mathrm{ng} / \mathrm{mL}$ to $6.0 \mathrm{ng} / \mathrm{mL}$, respectively (Table 2 ). The median stimulated $\mathrm{Tg}$ value was highest on day 6 of stimulation ( $72 \mathrm{~h}$ after RAI application).

There was a highly significant correlation between $\mathrm{Tg}$ level and thyroid remnant volume on ultrasound performed on the first day of rh-TSH stimulation (Table 3). In patients with thyroid remnant volume $>1 \mathrm{~mL}$, the median Tg concentration increased more than 63.6-fold on day 6 .

\section{Risk of thyroid cancer structural recurrence}

After a respective median follow-up of 6 years, structural recurrence was observed in $43 / 650$ patients $(6.6 \%)$ (Fig. 1) in the overall study sample and in $38 / 561$ patients $(6.8 \%)$ with $\operatorname{TgAbs}$ below the institutional cutoff. Median time to structural recurrence was 13 months. The recurrence rate was $6 \%, 9 \%$, and $18 \%$, respectively in the whole group of patients after 2, 3, and 5 years of follow-up. Most relapses $(34 / 43,79 \%)$ were found in the neck, $8(19 \%)$ were distant metastases, and one patient was diagnosed with both local recurrence and distant metastases.

In patients with $\mathrm{TgAbs}$ below the institutional cutoff, the recurrence rate was $10 \%, 13 \%$ and $22 \%$, respectively, after 2,3 , and 5 years of follow-up.

Table $2 \mathrm{Tg}$ concentration on day 1 , day 3 , and 6

\begin{tabular}{llccc}
\hline $\begin{array}{l}\text { Day of } \\
\text { stimulation }^{\text {a }}\end{array}$ & $\begin{array}{l}\text { Number of Tg evaluations } \\
\text { above detection threshold } \\
(\%)\end{array}$ & $\begin{array}{l}\text { Number of determinations } \\
\text { of Tg level }>10 \mathrm{ng} / \mathrm{mL}(\%)\end{array}$ & $\begin{array}{l}\text { Median (minimum- } \\
\text { maximum) Tg level (ng/ } \\
\mathrm{mL})\end{array}$ & $\begin{array}{l}\text { Median)(minimum-maximum)Tg level for } \\
\text { Tg evaluation above institutional detection } \\
\text { threshold }\end{array}$ \\
\hline Day 1 & $393(60.5)$ & $8(1.2)$ & $0.2(0.1-75.3)$ & $0.53(0.1-75.3)$ \\
Day 3 & $508(78)$ & $80(12)$ & $1(0.1-03)$ & $1.5(0.1-303)$ \\
Day 6 & $592(91)$ & $278(43)$ & $6(0.1-1492)$ & $7.7(0.1-1492)$ \\
\hline
\end{tabular}

$R A I$ radioiodine, $r h T S H$ recombinant human thyroid-stimulating hormone, $T g$ thyroglobulin

${ }^{a}$ The day 1 sample was taken immediately before the first injection of rhTSH, and the day 3 and day 6 samples were taken 24 and 96 h, respectively, after the second and final injection of rhTSH, and just before and72 hours, respectively, after RAI administration

${ }^{\dagger}$ The institutional detection threshold for $\mathrm{Tg}$ was $0.1 \mathrm{ng} / \mathrm{mL}$

Table $3 \mathrm{Tg}$ concentration in relation to thyroid remnant volume

\begin{tabular}{llrccc}
\hline Thyroid remnant volume $^{\mathrm{a}}$ & $\begin{array}{l}\text { Day of rhTSH } \\
\text { stimulation }\end{array}$ & $\mathrm{Tg}$, mean \pm SD & $\begin{array}{l}\text { Tg, median }(\mathrm{mini}- \\
\text { mum-maximum) }\end{array}$ & $p$ value \\
\hline None $(n=521)$ & 1 & 0.6 & \pm 1.6 & $0.2(<0.1-17.9)$ & $p<0.0001$ \\
& 3 & 2.8 & \pm 7.3 & $0.6(<0.1-77.8)$ & \\
$\leq 1 \mathrm{~mL}(n=94)$ & 6 & 25.8 & \pm 61.8 & $4.6(<0.1-494)$ & \\
& 1 & 1.4 & \pm 2.9 & $0.5(<0.1-23.9)$ & $p<0.0001$ \\
& 3 & 5.8 & $1 \pm 1.2$ & $2.0(<0.1-99.3)$ & \\
& 6 & 77.9 & \pm 137.0 & $25.0(<0.1-682.6)$ & \\
& 1 & 6.4 & \pm 15.8 & $1.5(<0.1-75)$ & $p<0.0001$ \\
& 3 & 29.4 & \pm 57.2 & $14.4(<0.1-302)$ & \\
& 6 & 260.8 & \pm 333.4 & $95.4(<0.1-1492)$ & \\
\hline
\end{tabular}

rhTSH recombinant human TSH, $T g$ thyroglobulin

${ }^{a}$ Volume was determined by neck ultrasound performed on day 1 of rh-TSH stimulation 
Fig. 1 Progression (structural recurrence)-free survival (PFS) in the whole group of patients $(N=650)$. Dotted lines represent the $95 \%$ confidence interval $(95 \% \mathrm{CI})$
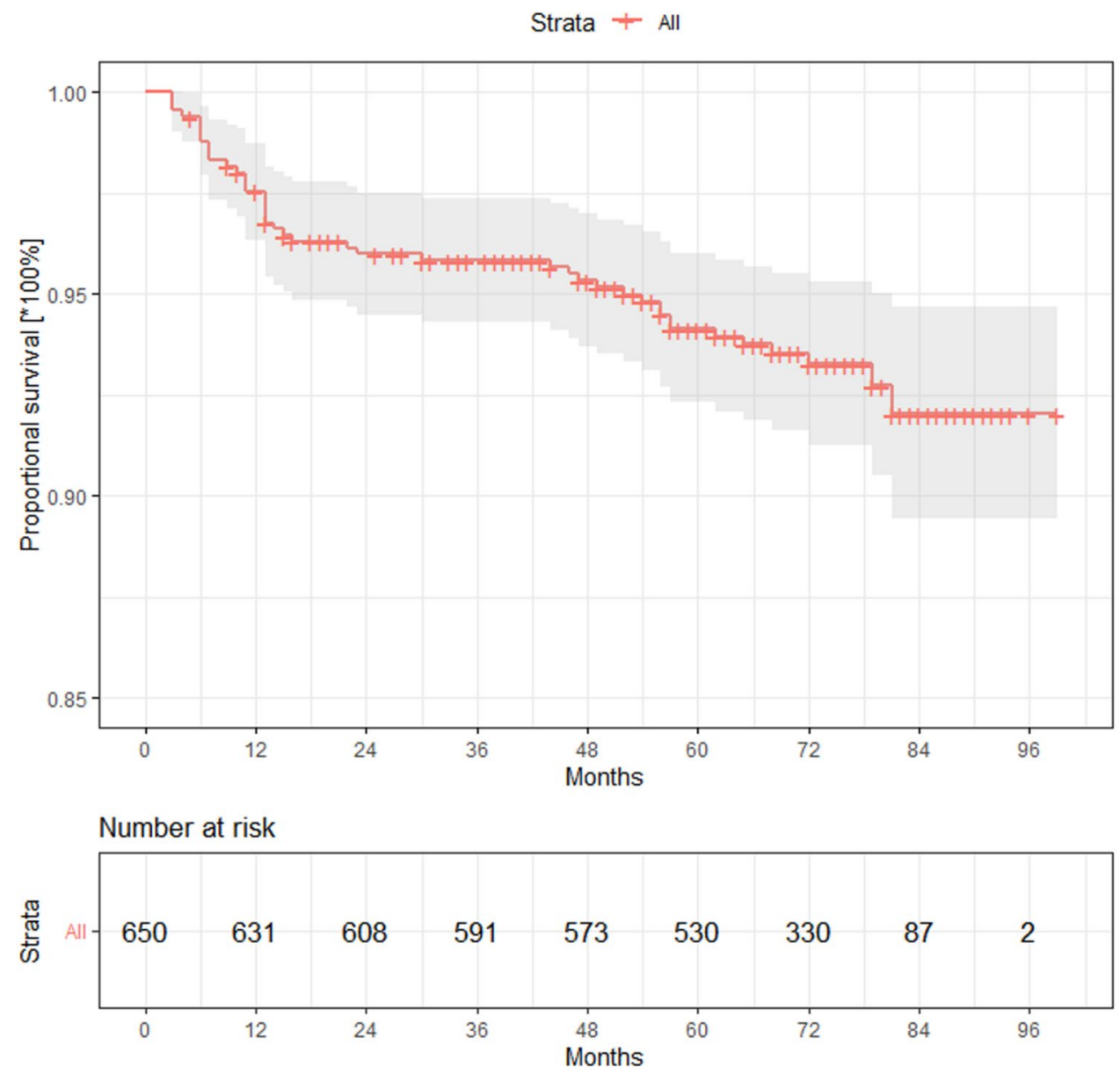

In another $6 / 650$ patients $(0.9 \%)$, stable elevated $\mathrm{Tg}$ $(>1 \mathrm{ng} / \mathrm{mL}$ ) was detected, but since these individuals were not diagnosed with structural recurrence, these cases were not considered treatment failures.

\section{Univariate and multivariate analysis for the risk of structural recurrence}

\section{The whole group of 650 patients (patients with detectable TgAbs included)}

In the univariate analyses, only $\mathrm{Tg}$ levels measured on day $1(\operatorname{Tg} 1)(p<0.001)$ and day $3(\mathrm{Tg} 3)(p<0.001)$ were significantly associated with structural recurrence. Such correlation was not observed for Tg level measured on day 6 . Among the analyzed biochemical factors, TSH concentration measured $24 \mathrm{~h}$ after the second injection of rhTSH (TSH3) was also significant for the risk of structural recurrence. In addition, age at diagnosis, sex, histology, presence of extrathyroidal extension, tumor size, presence of lateral lymph node metastases, and history of lateral lymph node dissection were found to be statistically significantly associated with structural recurrence in univariate analyses. The detailed results of these analyses are summarized in Table 4.

In the multivariate analysis, studied factors independently associated with structural recurrence were: $\mathrm{Tg}$ level measured on day 3, age at diagnosis, male gender, and history of lateral lymph node dissection. Tg concentration on day 6 was not significant (Table 5).

\section{Patients with negative TgAbs}

Similarly to the whole group of patients, in the subgroup negative for $\mathrm{TgAbs}$, only $\mathrm{Tg}$ levels measured on day 1 and day 3 were significantly associated with structural recurrence. In multivariate analysis, $\operatorname{Tg} 1$ was the only independent prognostic marker (Table 6).

\section{Analysis of ROC curves for optimal Tg concentration cutoff}

In the whole group of patients, in ROC curve analysis of the optimal cutoff to predict structural recurrence of DTC, the cutoff for Tg1 was $0.7 \mathrm{ng} / \mathrm{mL}$. The area under the curve 
(AUC), a measure of the cutoff's prognostic performance, was $61.7 \%$ (95\% CI, 51.6\%-71.7\%). Using this cutoff, Tg1 had a sensitivity of $53.5 \%$, a specificity of $75.9 \%$, an NPV of $96 \%$, and a PPV of $14 \%$ for predicting structural recurrence.

The cutoff of $\mathrm{Tg} 3$ was $1.4 \mathrm{ng} / \mathrm{mL}$ and the AUC was $61.8 \%(95 \%$ CI, 51.7\%-71.9\%). using this cutoff, $\mathrm{Tg} 3$ had a sensitivity of $67.4 \%$, a specificity of $62.8 \%$, an NPV of $96 \%$, and a PPV of $11 \%$ for predicting structural recurrence.

Results for the subgroup with TgAbs below $115 \mathrm{IU} / \mathrm{mL}$ $(n=591)$ did not differ from those in the whole group of patients. The ROC curves are shown in Fig. 2.

\section{Discussion}

In the present study, we showed that during rhTSH-aided adjuvant RAI treatment of DTC, Tg concentration after RAI application is highly variable and does not have prognostic significance. However, Tg concentration measured immediately before the first rhTSH injection or $24 \mathrm{~h}$ after the second rhTSH injection are independent prognostic factors, which allow selection of the group of patients with very good prognosis and low risk of structural recurrence. We focused only on structurally recurrent disease to choose the group of patients with unequivocal treatment failure that necessitates therapeutic intervention. Since most structural recurrences occur during the first 5 years after DTC diagnosis, the follow-up time in our study was long enough to pick up most such cases.

In the interpretation of postoperative $\mathrm{Tg}$ concentration, the time from surgery to ${ }^{131}$ I therapy is very important. The three main reasons for this importance are: (1) the half-life of $\mathrm{Tg}$ released into the blood during surgery, (2) the ability of the thyroid remnants to produce and release $\mathrm{Tg}$, and (3) the resolution of postoperative edema, which impedes the assessment of thyroid remnants and persistent neck disease. In our study sample, the median time from surgery to RAI therapy was 68 days, so such treatment took place at an optimal time for wound healing, Tg clearance from the blood stream, and detection of persistent disease.

Several studies in patients prepared with THW have demonstrated that stimulated Tg level measured just before
Table 4 Univariate analysis of entire cohort $(N=650)$ : significant prognostic factors for structural recurrence
Table 5 Multivariate analysis of entire cohort $(N=650)$ : significant prognostic factors for structural recurrence

\begin{tabular}{lllr}
\hline Prognostic factor & Hazard ratio & $95 \%$ confidence interval & $p$ value \\
\hline Papillary & 1.00 & $($ Ref. & \\
Follicular & 2.44 & $(1.08-5.53)$ & 0.032 \\
Poorly differentiated & 6.42 & $(1.54-26.8)$ & 0.011 \\
pT1 & 1.00 & $($ Ref.) & \\
pT2 & 3.93 & $(1.43-10.9)$ & 0.0081 \\
pT3/pT4 (extrathyroidal extension) & 6.96 & $(3.03-16.0)$ & $<0.0001$ \\
pTx & 6.28 & $(2.27-17.3)$ & 0.0004 \\
pN0 & 1.00 & $($ Ref.) & \\
pN1b & 4.84 & $(2.09-11.2)$ & 0.0002 \\
Female & 0.42 & $(0.22-0.80)$ & 0.0081 \\
Age (per additional yr) & 1.03 & $(1.01-1.06)$ & 0.0048 \\
Lateral lymph node dissection & 4.02 & $(2.1-7.70)$ & $<0.0001$ \\
Tg1 (ng/ml) & 1.06 & $(1.03-1.08)$ & $<0.0001$ \\
Tg3 (ng/ml) & 1.02 & $(1.01-1.023)$ & $<0.0001$ \\
TSH3 (mIU/ml) & 1.01 & $1.002-1.011)$ & 0.0094 \\
\hline
\end{tabular}

Tg6 was insignificant prognostic factor. ALL TNM classifications were according to the 7th edition

Ref. reference, $T g$ thyroglobulin, $T g 1$ thyroglobulin measured on day $1, T g 3$ thyroglobulin measured on day $3, T g 6$ thyroglobulin measured on day $6, T S H 3$ TSH measured on day 3

\begin{tabular}{lllr}
\hline Prognostic factor & Hazard ratio & $95 \%$ confidence interval & $p$ value \\
\hline Female & 0.51 & $(0.26-0.97)$ & 0.0414 \\
Age (per additional yr) & 1.04 & $(1.02-1.06)$ & 0.0003 \\
Lateral lymph node dissection & 5.32 & $(2.67-10.61)$ & $<0.0001$ \\
Tg3 (ng/ml) & 1.016 & $(1.009-1.024)$ & $<0.0001$ \\
\hline
\end{tabular}

$\operatorname{Tg} 1$ was insignificant prognostic factor

$\operatorname{Tg} 1$ thyroglobulin measured on day $1, T g 3$ thyroglobulin measured on day 3 
Table 6 Multivariate analysis of subgroup with $\mathrm{TgAbs}$ below institutional cutoff level $(n=561)$ : significant prognostic factors for structural recurrence

\begin{tabular}{lclr}
\hline Prognostic factor & Hazard ratio & $95 \%$ confidence interval & $p$ value \\
\hline Papillary & 1.00 & (Ref.) & \\
Poorly differentiated & 11.89 & $(2.61-54.2)$ & 0.0014 \\
pT1 & 1.00 & $($ Ref. & \\
pT2 & 3.11 & $(1.03-9.37)$ & 0.0435 \\
pT3/pT4 (extrathyroidal extension) & 4.83 & $(2.01-11.6)$ & 0.0004 \\
Age (per additional yr) & 1.04 & $(1.02-1.07)$ & 0.0016 \\
Lateral lymph node dissection & 5.27 & $(2.46-11.83)$ & $<0.0001$ \\
Tg1 (ng/ml) & 1.05 & $(1.02-1.08)$ & $<0.0021$ \\
\hline
\end{tabular}

$\mathrm{Tg} 3$ was insignificant prognostic factor. ALL TNM classifications were made according to the 7 th edition $\operatorname{Tg} 1$ thyroglobulin measured on day $1, T g 3$ thyroglobulin measured on day 3
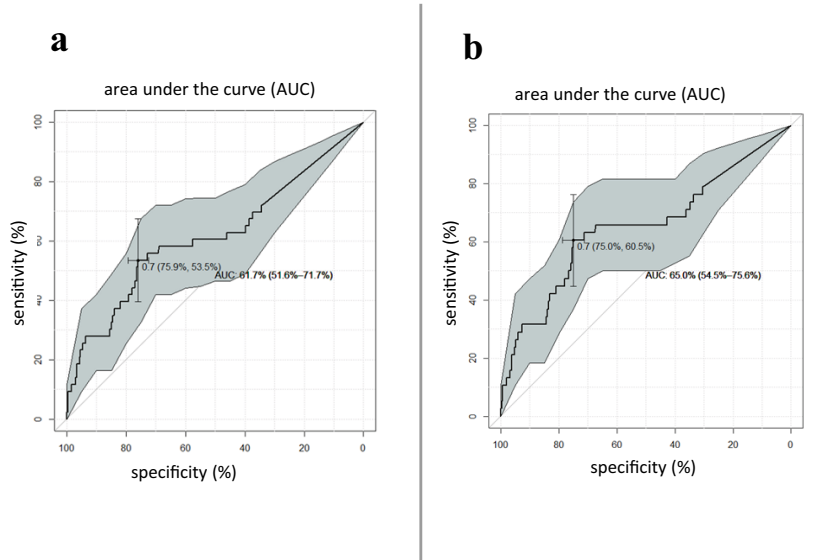

Fig. 2 Receiver-operating characteristic curve analysis for $\mathrm{Tg} 1$ ( $\mathrm{Tg}$ measured on day 1) in the whole group of patients (a) and in patients with anti-Tg antibodies (TgAbs) below the institutional cutoff (b), and

RAI has prognostic significance [4, 17-19] and currently, the measurement of serum $\mathrm{Tg}$ at the time of adjuvant RAI treatment is suggested in most DTC guidelines [3, 20]. In the diagnostic setting, $\mathrm{Tg}$ measurement $72 \mathrm{~h}$ after the second rhTSH injection is usually recommended, because that timepoint corresponds to the Tg peak level [21] and is predictive for persistent/recurrent disease. It would seem reasonable to have the same approach during RAI treatment, however, $\mathrm{Tg}$ released due to thyrocyte RAI damage may confound interpretation of the results [16].

Some studies demonstrated that $\mathrm{Tg}$ measurement after rhTSH stimulation and therapeutic RAI application is of prognostic significance $[9,11,13,22]$. Melo et al. [11] reported the prognostic value of $\operatorname{Tg} 5$ (i.e., measurement 5 days after first rhTSH injection) in predicting disease status 1 year post-ablation. The cutoff value of Tg5, 7.2 ng/ $\mathrm{mL}$, was associated with an NPV of $89.6 \%$, and was demonstrated to be an independent prognostic marker. In 2016 Moon et al. [9] published results confirming the utility of

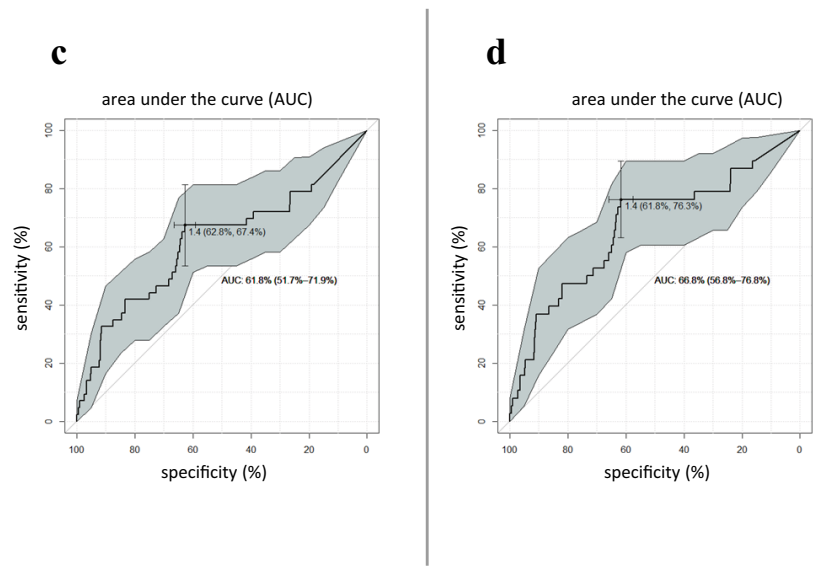

for $\operatorname{Tg} 3$ in the whole group of patients (c) and in patients with $\operatorname{TgAbs}$ below the institutional cutoff (d)

$\operatorname{Tg} 5$ measurement at ablation in patients after total thyroidectomy and prophylactic central neck dissection. The optimal cutoff value was $1.79 \mathrm{ng} / \mathrm{mL}$, with an NPV of $99.5 \%$. The difference between the above-mentioned cutoff values of $\operatorname{Tg} 5$ was explained by the presence or absence of prophylactic neck dissection and by surgeon experience in total thyroidectomy. Also recently, Mutstudy et al. [13] showed that Tg levels measured two days after RAI therapy have prognostic significance. ROC curve analysis showed an optimal Tg cutoff value of $3.7 \mathrm{ng} / \mathrm{mL}$, which was confirmed as an independent prognostic factor in multivariate analysis. However, in contrast to our study, follow-up time in those studies was rather short (9-18 months) and usually both structural and biochemical failures with $\mathrm{Tg}>1 \mathrm{ng} / \mathrm{mL}$ were included.

Our results agree with work showing that RAI therapyinduced thyrocyte damage and released Tg into the bloodstream. Some authors assume [5] that the devascularized normal thyroid remnant is less capable of producing and releasing $\mathrm{Tg}$ in comparison to lymph node metastases. In 
our study, $\operatorname{Tg} 6$ showed a very strong correlation with thyroid remnants volume in neck ultrasound performed on first day of rh-TSH stimulation, and was also high in patients with thyroid remnants diagnosed in neck RAI scan but not in ultrasound [23]. In the "real world", thyroid cancer patients are not always operated on in hospitals with expertise in thyroid surgery, and to decrease the risk of surgical complications, some thyroid remnants are left in place. In our study, $\mathrm{Tg}$ concentration was the highest $72 \mathrm{~h}$ after ${ }^{131}$ I treatment. However, in univariate analysis, the $\mathrm{Tg}$ concentration at that time was non-significant as a prognostic factor for structural recurrence. Of interest is the fact, that in multivariate analysis of the whole group of patients, $\mathrm{Tg} 3$ concentration was a significant prognosticator of recurrence, but in patients with $\mathrm{TgAbs}$ below the institutional cutoff, $\mathrm{Tg} 1$ was statistically significant. One cannot exclude, that in the whole group of patients, $\operatorname{Tg} 1$ could be underestimated as a result of TgAbs interference in $\mathrm{Tg}$ measurement by immunometric assays. Higher Tg3 values after TSH stimulation can reduce the effect of antibody positivity since the increasing $\mathrm{Tg}$ concentration on day 3 ( $24 \mathrm{~h}$ after the second injection of rhTSH) could diminish the degree of the interference in $\mathrm{Tg}$ measurement. The propensity for $\mathrm{TgAbs}$ interference is known to be lowest when Tg levels are higher [24].

$\mathrm{Tg}$ cutoffs on day 1 and day 3 of rhTSh stimulation were $0.7 \mathrm{ng} / \mathrm{mL}$ and $1.4 \mathrm{ng} / \mathrm{mL}$, respectively, which correspond to results from other studies [10,12]. However, it should be underlined, that $\mathrm{Tg}$ concentration below this cutoff value has a very high NPV (about 96\%), but PPV for higher Tg concentrations is rather low. In a majority of patients, elevated Tg levels decline over time [25], which could explain the low $\mathrm{PPV}$ of Tg measurement during preparation for RAI therapy. Higer cutoff values would result in higher PPV, however, with much lower sensitivity in this group of patients with a relatively good prognosis. From a clinical practice point of view, it means that in patients with low $\mathrm{Tg}$ concentration on day 1 and day 3 of rhTSH stimulation (before RAI application), we can have less intensive surveillance.

This study has some limitations related to its retrospective data collection. Nevertheless, it also has three important strengths. First, data were collected from consecutive patients treated during three years. Second, only patients without persistent disease in ultrasonographic, radiological, and scintigraphic evaluation were enrolled. Third, the high number of patients allowed the performance of reliable statistical analysis.

In conclusion, serum $\mathrm{Tg}$ levels measured on day 1 and day 3 of rhTSH stimulation (before RAI treatment) independently predict a low risk of structural recurrence of DTC. Tg measured shortly after RAI application is highly variable, has no prognostic value, and hence can be avoided.
Supplementary Information The online version contains supplementary material available at https://doi.org/10.1007/s12149-021-01663-y.

Acknowledgements Robert J. Marlowe, Spencer-Fontayne Corporation, Jersey City, NJ, USA edited this manuscript.

Funding There are no sources of funding for the article.

Open Access This article is licensed under a Creative Commons Attribution 4.0 International License, which permits use, sharing, adaptation, distribution and reproduction in any medium or format, as long as you give appropriate credit to the original author(s) and the source, provide a link to the Creative Commons licence, and indicate if changes were made. The images or other third party material in this article are included in the article's Creative Commons licence, unless indicated otherwise in a credit line to the material. If material is not included in the article's Creative Commons licence and your intended use is not permitted by statutory regulation or exceeds the permitted use, you will need to obtain permission directly from the copyright holder. To view a copy of this licence, visit http://creativecommons.org/licenses/by/4.0/.

\section{References}

1. Jeong E, Yoon JK, Lee SJ, Soh EY, Lee J, An YS. Risk factors for indeterminate response after radioactive iodine therapy in patients with differentiated thyroid cancer. Clin Nucl Med. 2019;44:714-8.

2. Krajewska J, Jarzab M, Kukulska A, Czarniecka A, Roskosz J, Puch Z, et al. Postoperative Radioiodine treatment within 9 months from diagnosis significantly reduces the risk of relapse in low-risk differentiated thyroid carcinoma. Nucl Med Mol Imaging. 2019;53:320-7.

3. Haugen BR, Alexander EK, Bible KC, Doherty GM, Mandel SJ, Nikiforov YE, et al. 2015 American Thyroid Association Management Guidelines for Adult Patients with Thyroid Nodules and Differentiated Thyroid Cancer: the American Thyroid Association Guidelines Task Force on Thyroid Nodules and Differentiated Thyroid Cancer. Thyroid. 2016;26:1-133.

4. Park HJ, Jeong GC, Kwon SY, Min JJ, Bom HS, Park KS, et al. Stimulated serum thyroglobulin level at the time of first dose of radioactive iodine therapy is the most predictive factor for therapeutic failure in patients with papillary thyroid carcinoma. Nucl Med Mol Imaging. 2014;48:255-61.

5. Webb R, Howard R, Stojadinovic A, Gaitonde D, Wallace M, Ahmedet J, et al. The utility of serum thyroglobulin measurement at the time of remnant ablation for predicting disease-free status in patients with differentiated thyroid cancer: a meta-analysis involving 3947 patients. J Clin Endocrinol Metab. 2012;97:2754-63.

6. Heemstra K, Liu YY, Stokkel M, Kievit J, Corssmit E, Pereira A, et al. Serum thyroglobulin concentrations predict disease-free remission and death in differentiated thyroid carcinoma. Clin Endocrinol. 2007;66:58-64.

7. Ciappuccini R, Trzepla G, Heutte N, Sevin E, Galais MP, Bardet $S$, et al. Postablation (131)I scintigraphy with neck and thorax SPECT-CT and stimulated serum thyroglobulin level predict the outcome of patients with differentiated thyroid cancer. Eur J Endocrinol. 2011;164:961-9.

8. Toubeau M, Touzery C, Arveux P, Chaplain G, Vaillant G, Berriolo A, et al. Predictive value for disease progression of serum thyroglobulin levels measured in the postoperative period and after (131)I ablation therapy in patients with differentiated thyroid cancer. J Nucl Med. 2004;45:988-94.

9. Moon JH, Choi JY, Jeong WJ, Ahn SH, Lee WW, Kim KM, et al. Recombinant human thyrotropin-stimulated thyroglobulin 
level at the time of radioactive iodine ablation is an independent prognostic marker of differentiated thyroid carcinoma in the setting of prophylactic central neck dissection. Clin Endocrinol. 2016;85:459-65.

10. Ciappuccini R, Hardouin J, Heutte N, Vaur D, Quak E, Rame JP, et al. Stimulated thyroglobulin level at ablation in differentiated thyroid cancer: the impact of treatment preparation modalities and tumor burden. Eur J Endocrinol. 2014;171:247-52.

11. Melo M, Costa G, Ribeiro C, Carrilho F, Martins MJ, da Rocha $\mathrm{AG}$, et al. Stimulated thyroglobulin at recombinant human TSHaided ablation predicts disease-free status one year later. J Clin Endocrinol Metab. 2013;98:4364-72.

12. Giovanella L, Ceriani L, Suriano S, Ghelfo A, Maffioli M, et al. Thyroglobulin measurement before rhTSH-aided 131I ablation in detecting metastases from differentiated thyroid carcinoma. Clin Endocrinol. 2008;69:659-63.

13. Mutsuddy P, Jeon S, Yoo SW, Zhang Y, Chowdhury MSA, Kim $\mathrm{J}$, et al. Optimization of serum thyroglobulin measured at different time points for prognostic evaluation in differentiated thyroid carcinoma patients. Medicine. 2020;99:e19652.

14. Castagna MG, Brilli L, Pilli T, Montanaro A, Cipri C, Fioravanti $\mathrm{C}$, et al. Limited value of repeat recombinant human thyrotropin (rhTSH)-stimulated thyroglobulin testing in differentiated thyroid carcinoma patients with previous negative rhTSH-stimulated thyroglobulin and undetectable basal serum thyroglobulin levels. J Clin Endocrinol Metab. 2008;93:76-81.

15. Kloos RT, Mazzaferri EL. A single recombinant human thyrotropin-stimulated serum thyroglobulin measurement predicts differentiated thyroid carcinoma metastases three to five years later. J Clin Endocrinol Metab. 2005;90:5047-57.

16. Taïeb D, Lussato D, Guedj E, Roux F, Mundler O, et al. Early sequential changes in serum thyroglobulin after radioiodine ablation for thyroid cancer: possible clinical implications for recombinant human thyrotropin-aided therapy. Thyroid. 2006;16:177-9.

17. Bernier MO, Morel O, Rodien P, Muratet JP, Giraud P, Rohmer $\mathrm{V}$, et al. Prognostic value of an increase in the serum thyroglobulin level at the time of the first ablative radioiodine treatment in patients with differentiated thyroid cancer. Eur J Nucl Med Mol Imaging. 2005;32:1418-21.

18. Kim YI, Im HJ, Paeng JC, Cheon GJ, Kang KW, Lee DS, et al. Serum thyroglobulin level after radioiodine therapy (Day 3) to predict successful ablation of thyroid remnant in postoperative thyroid cancer. Ann Nucl Med. 2015;29:184-9.

19. Kim TY, Kim WB, Kim ES, Ryu JS, Yeo JS, Kim SC, et al. Serum thyroglobulin levels at the time of 131I remnant ablation just after thyroidectomy are useful for early prediction of clinical recurrence in low-risk patients with differentiated thyroid carcinoma. J Clin Endocrinol Metab. 2005;90:1440-5.

20. Jarząb B, Dedecjus M, Słowińska-Klencka D, Lewiński A, Adamczewski Z, Anielski R, et al. Guidelines of Polish National Societies Diagnostics and Treatment of Thyroid Carcinoma. 2018 Update. Endokrynol Pol. 2018;69:34-74.

21. Haugen BR, Pacini F, Reiners C, Schlumberger M, Ladenson PW, Sherman SI, et al. A comparison of recombinant human thyrotropin and thyroid hormone withdrawal for the detection of thyroid remnant or cancer. J Clin Endocrinol Metab. 1999;84:3877-85.

22. Ha J, Kim MH, Jo K, Lim Y, Bae JS, Lee S, et al. Recombinant human TSH stimulated thyroglobulin levels at remnant ablation predict structural incomplete response to treatment in patients with differentiated thyroid cancer. Medicine. 2017;96:e7512.

23. Bulzacka I, Makarewicz J. Postablative 131I SPECT/CT Is much more sensitive than cervical ultrasonography for the detection of thyroid remnants in patients after total thyroidectomy for differentiated thyroid cancer. Clin Nucl Med. 2020;45:948-53.

24. Spencer CA. Clinical review: Clinical utility of thyroglobulin antibody $(\mathrm{TgAb})$ measurements for patients with differentiated cancer (DTC). J Clin Endocrinol Metab. 2011;2011(96):3615-27.

25. Momesso DP, Tuttle RM. Update on differentiated thyroid cancer staging. Endocrinol Metab Clin North Am. 2014;43(2):401-21. https://doi.org/10.1016/j.ecl.2014.02.010.

Publisher's Note Springer Nature remains neutral with regard to jurisdictional claims in published maps and institutional affiliations. 